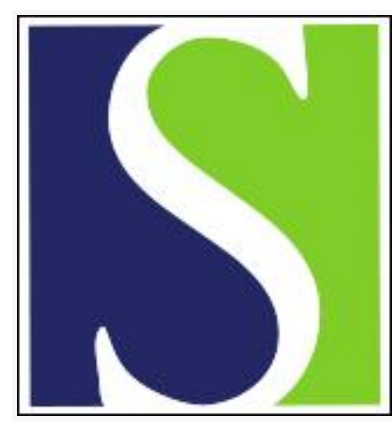

Scand J Work Environ Health 2000;26(2):137-145

https://doi.org/10.5271/sjweh.523

Issue date: Apr 2000

\title{
Maternal occupational risk factors for oral clefts
}

by Lorente C, Cordier S, Bergeret A, De Walle HEK, Goujard J, Aymé S, Knill-Jones R, Calzolari E, Bianchi F, Occupational Exposure and Congenital Malformation Working Group

The following article refers to this text: 2013;39(3):302-309

Key terms: epidemiology; occupational exposure

This article in PubMed: www.ncbi.nlm.nih.gov/pubmed/10817379

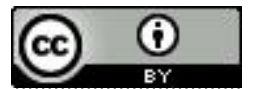




\title{
Maternal occupational risk factors for oral clefts
}

\author{
by Christine Lorente, MSc, ${ }^{1}$ Sylvaine Cordier, PhD, ${ }^{1}$ Alain Bergeret, ${ }^{2}$ Hermien EK De Walle, MSc, ${ }^{3}$ Janine \\ Goujard, MD, ${ }^{4,5}$ Ségolène Aymé, MD, ${ }^{6}$ Robin Knill-Jones, FRCP, ${ }^{7}$ Elisa Calzolari, MD, ${ }^{8}$ Fabrizio Bianchi, \\ $P h D,{ }^{9}$ Occupational Exposure and Congenital Malformation Working Group ${ }^{10}$
}

\begin{abstract}
Lorente C, Cordier S, Bergeret A, De Walle HEK, Goujard J, Aymé S, Knill-Jones R, Calzolari E, Bianchi F, Occupational Exposure and Congenital Malformation Working Group. Maternal occupational risk factors for oral clefts. Scand J Work Environ Health 2000;26(2):137-145.
\end{abstract}

\begin{abstract}
Objectives This study investigated the role of maternal exposures at work during pregnancy in the occurrence of oral clefts.

Methods The occupational exposures of 851 women (100 mothers of babies with oral clefts and 751 mothers of healthy referents) who worked during the first trimester of pregnancy were studied. All the women were part of a multicenter European case-referent study conducted using 6 congenital malformation registers between 1989 and 1992. In each center, the mother's occupational history, obtained from an interview, was reviewed by industrial hygienists who were blinded to the subject's status and who assessed the presence of chemicals and the probability of exposure. Odds ratios (OR) were estimated by a multivariate analysis including maternal occupation or occupational exposures during the first trimester of pregnancy and possible confounding factors such as center of recruitment, maternal age, urbanization, socioeconomic status, and country of origin.

Results After adjustment for confounding factors, cleft palate only was significantly associated with maternal occupation in services such as hairdressing [OR 5.1, 95\% confidence interval (95\% CI) $1.0-26.0$ ] and housekeeping (OR 2.8, 95\% CI 1.1-7.2). The analysis suggests that the following occupational exposures are associated with orofacial clefts: aliphatic aldehydes (OR 2.1, 95\% CI 0.8-5.9) and glycol ethers (OR 1.7, 95\% CI 0.9-3.3) for cleft lip with or without cleft palate and lead compounds (OR 4.0,95\% CI 1.3-12.2), biocides (OR 2.5, 95\% CI 1.0-6.0), antineoplastic drugs (OR 5.0,95\% CI 0.8 - 34.0), trichloroethylene (OR 6.7, 95\% CI 0.9-49.7), and aliphatic acids (OR $6.0,95 \%$ CI $1.5-22.8$ ) for cleft palate only.
\end{abstract}

Conclusions Due to the limited number of subjects, these results must be interpreted with caution. However, they point out some chemicals already known or suspected as reproductive toxins.

Key lerms epidemiology, occupational exposures.

Oral clefts are among the most frequent congenital anomalies, with a prevalence of approximately 1 per 700 births in Europe (1). Investigators agree that oral clefts are multifactorial in origin and are caused by both genetic and environmental factors. Many genetic (risk of recurrence) and epidemiologic (sex ratio, prevalence)
Reprint requests to: Ms Christine Lorente, INSERM U 170, 16, avenue Paul Vaillant Couturier 94807 Villejuif, Cedex France. [E-mail: lorente@vjf.inserm.fr]

Institut Universitaire de Médicine du Travail, Lyon, France.

Department of Medical Genetics, State University of Groningen, Groningen, The Netherlands.

Inserm U149, Recherches Epidémiologiques sur la santé des femmes et des enfants, Villejuif, France.

Registre des malformations congénitales de Paris, Villejuif, France.

Inserm SC11, Cartographie du génome humain à des fins de recherche clinique, Villejuif, France.

Department of Public Health, University of Glasgow, Glasgow, Great Britain.

Institut di Genetica Medica, Ferrara, Italy.

Epidemiologia Instituto di Fisiologia Clinica del consiglio Nazionale delle Richerche, Università di Pisa, Pisa, Italy.

Bouches du Rhône (France): S Aymé, J Pompili; Emilia Romagna (Italy): E Calzolari, S Candela; Glasgow (United Kindom): R Knill Jones, I Dale, A Nielsen; Groningen (The Netherlands): Hek de Walle, MC Cornel, EY Haayer, GS Kiel, MYMC Smeets, TM Pal; Lyon (France): A Bergeret, B Danaché, J Fevotte; Paris (France): J Goujard, C de Vigan, V Vodovar, O Boiron; Toscana (Italy): F Bianchi, A Seniori-Costantini, A Scarpelli, A Pierini; Villejuif (France): S Cordier, MC Ha, L Mandereau.

Inserm U170 Unité de recherches Epidémiologiques et Statistiques sur l'Environnement et la Santé, Villejuif, France. 
characteristics tend to suggest that cleft lip with or without cleft palate [CL(P)] and cleft palate only (CP) are etiologically distinct, although most early studies in environmental risk factors have considered them a group. Some of the environmental factors implicated in the causation of nonsyndromic oral clefts include tobacco use [for all types of clefts $(2-5)$ and also for $\mathrm{CL}(\mathrm{P})(3,4)$ ], antiepileptic drugs $(6,7)$, and possibly alcohol consumption [for $\mathrm{CL}(\mathrm{P})](8,9)$. Debate continues as to whether multivitamin supplements, especially folic acid, can prevent oral clefts $(10-12)$.

Various occupations and exposures have been associated with reproductive risks (13-17). For oral clefts, the occupations include those in the agricultural $(18,19)$ and health care fields (13). Maternal exposure to solvents has also been associated with clefts $(20-22)$. Nonetheless, not enough is yet known about the occupational risk factors related to orofacial clefts. The present analysis is a part of a larger study; our objective here is to investigate the role of maternal workplace exposures during pregnancy in the occurrence of oral clefts.

\section{subjects and methods}

Data for this analysis were obtained from a multicenter European case-referent study conducted by 6 European congenital malformation registries, all members of EUROCAT (European Registration of Congenital Anomalies): 2 in France (Paris and Bouches du Rhône), 1 in the United Kingdom (Glasgow), 2 in Italy (Emilia Romagna and Tuscany), and 1 in The Netherlands (Groningen). The methods used in this investigation have been described in detail in a previous publication (23).

Cases were defined as any product of conception (live or stillborn child or fetus from a therapeutic abortion performed because of the malformation) with a major congenital malformation diagnosed prenatally or during the perinatal period ( 0 to 6 days). Cases were identified between 1989 and 1992 by the 6 registries. For practical reasons, the registries in France and Italy recruited cases from only some of their hospitals. Each malformation was coded locally according to the British Paediatric Association Classification of Diseases (BPACD) (24). Coding and inclusion criteria were then verified centrally.

A healthy reference baby, without malformations, was recruited for each case in every center except Glasgow, where 2 referents were recruited for each case. For the hospital-based cases, the referent was the next child born without malformations. For the cases recruited from a general population (Glasgow and Groningen), the referent was a child born on the same date and in the same town.

The medical file provided information about the baby: date of birth, gender, birthweight, gestational age, description of the malformation, status (liveborn, stillborn, abortion),

Specially trained investigators used a standardized questionnaire to interview mothers. The same investigator saw both mothers of a case-referent pair, and all the interviews took place in the hospital during the week following the birth or abortion for the hospital-based centers or at home and during the month after birth for the centers that recruited referents from the general population. The interview provided information about the parents' sociodemographic characteristics, age, residence, and country of origin, as well as the mother's medical and obstetric history, alcohol, tobacco and drug use, and occupation and hobbies, both before conception and during each trimester of the pregnancy. The interviews elicited a detailed description of occupations before and during pregnancy - industrial activity and specific occupation. It included a description of tasks, products handled, frequency of use, and period (1 month before conception and 1st, 2 nd or 3 rd trimester). There were also supplemental questionnaires for typical job categories (cleaners and janitors, hairdressers and beauticians, cooks, waiters, and teachers) and for some jobs especially common at specific centers ( $\mathrm{eg}$, leather work, ceramics, and plastics manufacturing). All the interviewers had all

Table 1. Distribution of the cases and referents by center and type of malformation (working mothers only).

\begin{tabular}{|c|c|c|c|c|c|c|c|c|c|}
\hline \multirow[t]{3}{*}{ Center } & \multicolumn{6}{|c|}{ Cases } & \multicolumn{3}{|c|}{ Referents } \\
\hline & \multicolumn{3}{|c|}{$\begin{array}{l}\text { Cleft lip with or } \\
\text { without cleft palate }\end{array}$} & \multicolumn{3}{|c|}{$\begin{array}{l}\text { Cleft palate } \\
\text { only }\end{array}$} & \multirow[t]{2}{*}{ Matched } & \multirow[t]{2}{*}{ Unmatched } & \multirow[t]{2}{*}{ Total } \\
\hline & |solated & Multiple & Total & Isolated & Multiple & Total & & & \\
\hline Paris & 10 & 7 & 17 & 7 & 1 & 8 & 24 & 253 & 277 \\
\hline Bouches du Rhône & 10 & - & 10 & 5 & 2 & 7 & 15 & 74 & 59 \\
\hline Emilia Romagna and Tuscany & 4 & - & 4 & 8 & - & 8 & 13 & 111 & 124 \\
\hline Groningen & 24 & 3 & 27 & 7 & 1 & 8 & 37 & 116 & 153 \\
\hline Glasgow & 6 & - & 6 & 3 & 2 & 5 & 26 & 164 & 138 \\
\hline Total & 54 & 10 & 64 & 30 & 6 & 36 & 115 & 636 & 751 \\
\hline
\end{tabular}


the questionnaires and used them when relevant jobs were reported, at any center.

Despite efforts at exhaustiveness, only $63 \%$ of the eligible cases of oral cleft could be interviewed, mostly because the mother left the hospital before the interview or because the mother or her physician refused to participate. Refusals were rare among the hospital referents (less than $10 \%$ in Paris). In the population-based studies, however, more of the referents did not participate. In Groningen, about 150 of the referenece mothers contacted did not respond to the request for participation and were replaced by the next child meeting the same criteria; in Glasgow, 39 referents (15 refused, 24 not traced) had to be replaced. In all, between 1989 and 1992, a total of 984 cases of malformation, including 161 oral clefts (BPACD code 749.01 to 749.29 ), and 1134 referents were included in this study.

One hundred cases and 751 referents $(66 \%$ of the total) worked during pregnancy (table 1) and were included in the present analysis. Most of the cases were liveborn babies (98.5\%). Due to the small number of subjects, the Italian centers (Tuscany and Emilia Romagna) were combined in subsequent analyses. More than $80 \%$ of the malformations were isolated rather than syndromic forms.

Because our analysis concerned only cases of oral clefts, we had 2 types of referents available, those matched with the cases of oral clefts, whom we will refer to as matched referents $(\mathrm{N}=183)$, and those referents matched with the other cases of malformations, called the unmatched referents ( $N=951$ ). These 2 categories of referents did not differ significantly for characteristics such as maternal age, socioeconomic status, country of origin (maternal and paternal), urbanization (residence in a municipality with $<200000$ inhabitants; $\geq 200000$ inhabitants), and mother's employment during pregnancy. To increase the power of the analysis, therefore, we chose to consider the overall reference group ( $N=1134)$.

The working mothers of the cases and referents did not differ notably for either sociodemographic variables or for obstetric history, except for place of residence [mothers of CL(P) cases came from less urban backgrounds than their referents] and mother's age [older for $\mathrm{CL}(\mathrm{P})$ cases] (table 2). Moreover, no relevant differences were observed for the paternal sociodemographic variables.

The coding of occupations and industrial activities followed the code of the International Standard Classification of all Economic Activities (25) for industrial activity and the code of the International Standard Classification of Occupations (26) for occupations. In each center, an industrial hygiene expert blinded to the casereferent status interpreted the description of jobs during pregnancy and identified each potential workplace exposure (from a prepared list of 314 exposures) and the period of pregnancy when the exposure took place. Each exposure was defined by the following 4 parameters: (i) route of exposure: inhalation, cutaneous, both; (ii) level: low, medium, high; (iii) frequency: $<5 \%, 5-50 \%,>50 \%$ of worktime; (iv) reliability of the assessment: possible, probable, or certain exposure. All occupational codes and center-specific exposures were centrally reviewed and standardized.

The analysis of occupational exposures was restricted to women who worked during pregnancy (100 cases and 751 referents). The association between occupation, occupational exposures, and orofacial clefts was studied by calculating the Mantel-Haenszel odds ratio (OR) and its $95 \%$ confidence interval $(95 \% \mathrm{CI})$, separately for each type of cleft $[\mathrm{CL}(\mathrm{P})$ and $\mathrm{CP}]$. The reference group for the odds ratios for each occupation were all women

Table 2. Sociodemographic characteristics of the working mothers. $[\mathrm{CL}(\mathrm{P})=$ cleft lip with or without cleft palate, $\mathrm{CP}=$ cleft palate only]

\begin{tabular}{|c|c|c|c|}
\hline \multirow[t]{2}{*}{ Characteristic } & \multicolumn{2}{|c|}{ Cases } & \multirow{2}{*}{$\begin{array}{c}\text { Referents } \\
(\mathrm{N}=751) \\
(\%)\end{array}$} \\
\hline & $\begin{array}{c}\mathrm{CL}(\mathrm{P}) \\
(\mathrm{N}=36) \\
(\%)\end{array}$ & $\begin{array}{c}\mathrm{CP} \\
(\mathrm{N}=64) \\
(\%)\end{array}$ & \\
\hline \multicolumn{4}{|c|}{ Mother's socioeconomic status (last job before delivery) } \\
\hline $\begin{array}{l}\text { Scientific, technical, professional, } \\
\text { managerial, student }\end{array}$ & 25.7 & 31.3 & 38.3 \\
\hline Administrative, sales, services & 68.6 & 56.2 & 54.7 \\
\hline Agricultural, production workers & 5.7 & 12.5 & 7.0 \\
\hline \multicolumn{4}{|l|}{ Mother's country of origin } \\
\hline Same as child's & 91.7 & 84.3 & 88.2 \\
\hline Foreign & 8.3 & 15.6 & 11.8 \\
\hline \multicolumn{4}{|l|}{ Mother's age } \\
\hline$\leq 24$ years & 22.2 & 4.7 & 14.7 \\
\hline $25-29$ years & 33.3 & 59.4 & 39.2 \\
\hline $30-34$ years & 25.0 & 25.0 & 31.6 \\
\hline$\geq 35$ years & 19.4 & 10.9 & 14.5 \\
\hline \multicolumn{4}{|l|}{ Mother's residence } \\
\hline $\begin{array}{l}\text { Municipality of } \\
\leq 200000 \text { inhabitants }\end{array}$ & 61.1 & 78.1 & 63.8 \\
\hline $\begin{array}{l}\text { Municipality of } \\
>200000 \text { inhabitants }\end{array}$ & 38.9 & 21.9 & 36.2 \\
\hline \multicolumn{4}{|l|}{ Previous medical abortion } \\
\hline Yes & 0 & 3.2 & 4.3 \\
\hline No & 100 & 96.8 & 95.7 \\
\hline \multicolumn{4}{|l|}{ Previous spontaneous abortion } \\
\hline Yes & 22.2 & 22.2 & 20.9 \\
\hline No & 77.8 & 77.8 & 79.1 \\
\hline \multicolumn{4}{|l|}{ Previous stillbirth } \\
\hline Yes & 2.8 & 0 & 1.7 \\
\hline No & 97.2 & 100 & 98.3 \\
\hline \multicolumn{4}{|l|}{ Parity } \\
\hline Primiparous & 58.3 & 49.2 & 56.6 \\
\hline Multiparous & 41.7 & 50.8 & 43.4 \\
\hline \multicolumn{4}{|c|}{ Tobacco smoking during 1st trimester of pregnancy } \\
\hline Yes & 30.0 & 38.3 & 30.5 \\
\hline No & 70.0 & 61.7 & 69.5 \\
\hline \multicolumn{4}{|c|}{ Alcohol drinking during 1st trimester of pregnancy } \\
\hline Yes & 34.5 & 21.0 & 22.0 \\
\hline No & 65.5 & 79.0 & 78.0 \\
\hline
\end{tabular}


working during pregnancy in any occupation except that under study. To minimize the possible effects of selection, which might be related, for example, to hospital recruitment, we adjusted these odds ratios for center, mother's socioeconomic status (professional, clerical and student, sales and service, production or agriculture), urbanization (<200 000 habitants; $\geq 200000$ habitants), and country of origin. Moreover, because maternal age has been suggested as a possible risk factor for oral clefts $(27-29)$, it was taken into account in the adjustment (4 age classes: $\leq 24$ years, $25-29$ years, $30-34$ years, $\geq 35$ years).

The occupational exposures considered for the analysis were those reported by the experts for more than $10 \%$ ( $\mathrm{N} \geq 8$, cases and referents combined) of working mothers for the first trimester of pregnancy. Women were considered exposed, regardless of the frequency or probability of exposure, as long as neither was zero. For each product, the "unexposed" category comprised all women not exposed to that product, regardless of their exposure to any other product.
Because most women had been exposed simultaneously to several chemicals, our goal - in addition to estimating individual risk - was to identify, at the end of the process, a limited number of chemicals independently associated with an increased risk of orofacial clefts. Many of these exposures were highly correlated, either because of our study design (ie, exposure to formaldehyde automatically entailed exposure to "aliphatic aldehydes") or because of the work environments represented in our sample (ie, bleaching agents and ammonia were considered present almost exclusively for hairdressers and almost always together). We decided in the first situation to consider only the broader exposure, representative of the chemical family, and in the second situation to consider only 1 exposure to be representative of hairdressers.

The adjusted odds ratios for each of these exposures were estimated for CL(P) and CP. To estimate the independent effects of these exposures, we selected for further analysis those associated with an odds ratio for which the P-value was $\leq 20 \%$. We used a backward

Table 3. Odds ratios associated with maternal occupation in the first trimester of pregnancy (subcategories reported only when at least $10 \%$ of all subjects were employed in that category). $[C L(P)=$ cleft lip with or without cleft palate, $C P=$ cleft palate only, $95 \% \mathrm{Cl}=95 \%$ confidence interval]

\begin{tabular}{|c|c|c|c|c|c|c|c|c|}
\hline \multirow[t]{2}{*}{ Maternal occupation } & \multirow[t]{2}{*}{$\begin{array}{c}C L(P) \\
(N=64)\end{array}$} & \multirow[t]{2}{*}{$\begin{array}{c}\mathrm{CP} \\
(\mathrm{N}=36)\end{array}$} & \multicolumn{2}{|c|}{$\begin{array}{c}\text { Referents } \\
(\mathrm{N}=751)\end{array}$} & \multirow[t]{2}{*}{$\begin{array}{l}\text { Odds ratio } \\
C L(P)^{\mathrm{a}}\end{array}$} & \multirow[t]{2}{*}{$\begin{array}{c}95 \% \mathrm{Cl} \\
\mathrm{CL}(\mathrm{P})\end{array}$} & \multirow[t]{2}{*}{$\begin{array}{c}\text { Odds ratio } \\
\mathrm{CPa}^{\mathrm{a}}\end{array}$} & \multirow[t]{2}{*}{$\begin{array}{c}95 \% \mathrm{Cl} \\
\mathrm{CP}\end{array}$} \\
\hline & & & $\mathrm{N}$ & $\%$ & & & & \\
\hline Professional, technical and related workers & 18 & 9 & 267 & 36 & 0.69 & $0.38-1.25$ & 0.68 & $0.30-1.53$ \\
\hline Medical, dental, veterinarians, pharmacists & 3 & 1 & 52 & . & 0.76 & $0.22-2.60$ & 0.47 & $0.06-3.56$ \\
\hline Nurses, midwives, medical X-ray technicians & 4 & 1 & 64 & . & 0.73 & $0.25-2.14$ & 0.35 & $0.05-2.61$ \\
\hline Architects, engineers and related technicians & 2 & - & 12 & . & 2.43 & $0.47-12.5$ & . & . \\
\hline Statisticians, mathematicians, system analysts & - & - & 8 & . & . & . & . & . \\
\hline Teachers & 4 & 2 & 73 & . & 0.52 & $0.18-1.53$ & 0.55 & $0.13-2.42$ \\
\hline Social workers & 1 & 1 & 17 & . & 0.42 & $0.05-3.43$ & 1.14 & $0.14-9.49$ \\
\hline Others professional and technical workers & 4 & 4 & 41 & . & 1.51 & $0.49-4.64$ & 2.43 & $0.75-7.87$ \\
\hline Students & - & - & 9 & 1 & . & . & . & . \\
\hline Administrative, managerial workers & 2 & - & 11 & 2 & 2.78 & $0.53-14.6$ & . & . \\
\hline Clerical and related workers & 15 & 8 & 227 & 30 & 0.70 & $0.37-1.30$ & 0.73 & $0.32-1.65$ \\
\hline Stenographers, typists & 2 & 2 & 46 & . & 0.42 & $0.09-1.90$ & 0.94 & $0.21-4.33$ \\
\hline Bookkeepers, cashiers & 5 & 2 & 73 & . & 1.00 & $0.37-2.68$ & 0.51 & $0.12-2.22$ \\
\hline Computing machine operators & - & 1 & 9 & . & & & 3.91 & $0.44-35.0$ \\
\hline Other clerical and related workers & 8 & 3 & 99 & . & 0.83 & $0.37-1.86$ & 0.71 & $0.21-2.42$ \\
\hline Sales workers & 6 & 2 & 75 & 10 & 1.0 & $0.40-2.46$ & 0.56 & $0.13-2.41$ \\
\hline Technical salesmen, commercial travellers & 1 & - & 13 & . & 1.15 & $0.14-9.67$ & & \\
\hline Salesmen, shop assistant & 5 & 2 & 45 & . & 1.43 & $0.51-3.99$ & 0.90 & $0.21-3.98$ \\
\hline Other sales workers & - & - & 17 & . & & . & . & . \\
\hline Service workers & 16 & 14 & 106 & 14 & 1.71 & $0.90-3.24$ & 3.92 & $1.83-8.38$ \\
\hline Housekeeping workers & 6 & 7 & 52 & . & 1.16 & $0.45-2.97$ & 2.80 & $1.08-7.24$ \\
\hline Nurses' aides & 3 & 2 & 14 & . & 1.68 & $0.44-6.36$ & 2.91 & $0.58-14.6$ \\
\hline Hairdressers, beauticians & 2 & 2 & 9 & . & 1.86 & $0.36-9.65$ & 5.10 & $1.01-25.9$ \\
\hline Cooks, waiters & 2 & 2 & 17 & . & 1.74 & $0.35-8.70$ & 3.28 & $0.67-16.1$ \\
\hline Other service workers & 3 & 1 & 14 & . & 2.43 & $0.64-9.22$ & 1.57 & $0.19-12.9$ \\
\hline Agricultural workers & 1 & - & 6 & 1 & 1.37 & $0.14-13.2$ & . & . \\
\hline Production workers & 6 & 2 & 46 & 6 & 2.51 & $0.94-6.72$ & 0.78 & $0.17-3.52$ \\
\hline Textile workers & 1 & 1 & 12 & . & 1.80 & $0.20-16.2$ & 1.65 & $0.19-14.5$ \\
\hline Leather workers & - & - & 10 & . & & & & \\
\hline Other production workers & 5 & 1 & 24 & . & 3.17 & $1.06-9.51$ & 0.95 & $0.12-7.51$ \\
\hline
\end{tabular}

adjusted for center, maternal age, mother's socioeconomic status, urbanization, and country of origin. 
stepwise logistic regression starting with a full model including all the exposures selected at the previous step and all the sociodemographic variables already discussed to obtain a final set of exposures independently associated with oral clefts.

\section{Results}

Most of the working mothers had administrative and professional or technical jobs. Only $14 \%$ worked in service industries, and $6 \%$ were in production (table 3 ). The odds ratios were estimated for each type of cleft and were highest for service occupations. Within this group, the odds ratios were higher for $\mathrm{CP}$ than for $\mathrm{CL}(\mathrm{P})$ and statistically significant for CP for only 2 occupations: housekeepers (OR 2.80, 95\% CI 1.08-7.24) and hairdressers
(OR 5.10 95\% CI 1.01-25.9). For production workers, the elevated odds ratios primarily concerned CL(P).

Of the prepared list of 314 exposures, 96 chemicals, chemical groups, and end-use products were assessed as present in the workplaces of more than $10 \%$ of the subjects. Odds ratios adjusted for the potential confounders already discussed were estimated for each of these 96 exposures and for each type of cleft. Table 4 lists those products for which the P-value was $\leq 20 \%$ for at least 1 type of cleft. Odds ratios significantly different from 1 $(\mathrm{P}<0.05)$ were observed for aliphatic aldehydes, glycol ethers, cleaning agents, products used for duplicating processes, and formaldehyde for the CL(P) group and for hair dust, fluorocarbons, lead compounds, aliphatic alcohols, toluene, hydrogen peroxide, trichloroethylene, alkanes (C1-C4), aliphatic acids, biocides, antineoplastic drugs, ammonia, bleaching agents, and spray gases for the $\mathrm{CP}$ group.

Table 4. Adjusted odds ratios for occupational exposures in the 1st trimester in association with oral clefts (presented for exposures to which at least $10 \%$ of all the subjects were exposed and $P \leq 20 \%$ for at least one type of cleft). $[\mathrm{CL}(P)=$ cleft lip with or without cleft palate, $C P=$ cleft palate only, $95 \% \mathrm{Cl}=95 \%$ confidence interval]

\begin{tabular}{|c|c|c|c|c|c|c|c|}
\hline Exposure & $\begin{array}{c}C L(P) \\
(N=64)\end{array}$ & $\begin{array}{c}C P \\
(N=36)\end{array}$ & $\begin{array}{c}\text { Referents } \\
(\mathrm{N}=751) \\
(\%)\end{array}$ & $\begin{array}{l}\text { Odds ratio } \\
C L(P)^{a}\end{array}$ & $\begin{array}{c}95 \% \mathrm{Cl} \\
\mathrm{CL}(\mathrm{P})\end{array}$ & $\begin{array}{c}\text { Odds ratio } \\
\mathrm{CPa}^{2}\end{array}$ & $\begin{array}{c}95 \% \mathrm{Cl} \\
\mathrm{CP}\end{array}$ \\
\hline Hair dust & 2 & 2 & 6 & 2.67 & $0.46-15.6$ & 6.87 & $1.21-39.2$ \\
\hline Nitrogen oxides & 10 & 7 & 78 & 1.50 & $0.71-3.19$ & 2.20 & $0.90-5.38$ \\
\hline Fluorocarbons & 6 & 5 & 27 & 2.07 & $0.77-5.57$ & 4.10 & $1.38-12.2$ \\
\hline Lead compounds & 6 & 5 & 45 & 1.66 & $0.63-4.33$ & 3.03 & $1.07-8.57$ \\
\hline Aliphatic aldehydes & 7 & 4 & 32 & 2.69 & $1.01-7.21$ & 2.29 & $0.71-7.41$ \\
\hline Aliphatic alcohols & 15 & 10 & 101 & 1.67 & $0.86-3.26$ & 2.51 & $1.13-5.59$ \\
\hline Toluene & 1 & 2 & 7 & 1.61 & $0.15-17.7$ & 6.73 & $1.19-38.0$ \\
\hline Monocyclic aromatic hydrocarbons & 5 & 4 & 32 & 1.79 & $0.62-5.16$ & 3.02 & $0.93-9.84$ \\
\hline Alkalis and caustics & 8 & 6 & 47 & 1.49 & $0.62-3.59$ & 2.67 & $0.97-7.38$ \\
\hline Hydrogen peroxide & 3 & 3 & 12 & 1.99 & $0.50-7.88$ & 4.62 & $1.12-19.0$ \\
\hline Trichlorethylene & 2 & 2 & 5 & 3.21 & $0.49-20.9$ & 6.47 & $1.02-40.9$ \\
\hline Blood and by-products & 5 & 5 & 59 & 0.97 & $0.35-2.68$ & 2.42 & $0.80-7.29$ \\
\hline Polish & 3 & 3 & 12 & 2.25 & $0.52-9.81$ & 3.29 & $0.79-13.7$ \\
\hline Mineral oils & 4 & 3 & 25 & 1.12 & $0.33-3.78$ & 4.14 & $0.95-18.1$ \\
\hline Alkanes C1-C4 & 4 & 4 & 22 & 1.55 & $0.49-4.97$ & 3.55 & $1.08-11.7$ \\
\hline Aliphatic acids & 2 & 4 & 12 & 1.50 & $0.31-7.39$ & 8.17 & $2.31-28.9$ \\
\hline Aliphatic amines & 2 & 2 & 9 & 1.79 & $0.33-9.60$ & 3.77 & $0.69-20.5$ \\
\hline Glycol ethers & 23 & 11 & 137 & 2.10 & $1.14-3.88$ & 1.82 & $0.82-4.03$ \\
\hline Pharmaceutical products & 7 & 6 & 85 & 1.05 & $0.44-2.55$ & 2.24 & $0.80-6.29$ \\
\hline Laboratory products & 1 & 2 & 13 & 0.68 & $0.08-5.61$ & 3.30 & $0.65-16.7$ \\
\hline Biocides & 20 & 13 & 135 & 1.73 & $0.95-3.17$ & 2.99 & $1.37-6.51$ \\
\hline Antineoplastic drugs & 1 & 2 & 7 & 3.35 & $0.37-3.12$ & 11.20 & $1.98-63.7$ \\
\hline Microbiological contaminants & 11 & 7 & 81 & 1.45 & $0.67-3.12$ & 2.47 & $0.93-6.59$ \\
\hline House dust & 14 & 3 & 68 & 1.99 & $0.97-4.09$ & 0.57 & $0.15-2.08$ \\
\hline Ammoniac & 3 & 2 & 7 & 3.08 & $0.66-14.4$ & 6.29 & $1.13-35.2$ \\
\hline Adhesives & 4 & 3 & 67 & 0.47 & $0.16-1.42$ & 0.85 & $0.24-3.05$ \\
\hline Inorganic acids & 4 & 1 & 9 & 2.92 & $0.79-10.9$ & 1.80 & $0.20-16.1$ \\
\hline Cleaning agents & 26 & 11 & 162 & 1.92 & $1.05-3.51$ & 1.50 & $0.67-3.37$ \\
\hline Duplicating process & 10 & 10 & 201 & 0.40 & $0.19-0.84$ & 1.08 & $0.48-2.42$ \\
\hline Polyvinyl acetate & 2 & 2 & 9 & 2.20 & $0.40-11.9$ & 5.14 & $0.96-27.4$ \\
\hline Engine emission & 5 & 4 & 37 & 1.87 & $0.67-5.22$ & 2.78 & $0.90-8.61$ \\
\hline Aromatic amines & 2 & 2 & 7 & 2.40 & $0.43-13.3$ & 5.27 & $0.95-29.2$ \\
\hline Bleaching agents & 2 & 7 & 2 & 2.29 & $0.41-12.7$ & 6.17 & $1.12-33.9$ \\
\hline Spray gases & 4 & 4 & 11 & 2.94 & $0.81-10.7$ & 5.62 & $1.54-20.6$ \\
\hline Formaldehyde & 7 & 4 & 28 & 3.06 & $1.13-8.24$ & 2.70 & $0.83-8.73$ \\
\hline Ethanol & 14 & 8 & 90 & 1.77 & $0.89-3.51$ & 2.12 & $0.90-5.02$ \\
\hline Methanol & 4 & 2 & 8 & 3.61 & $0.91-14.4$ & 3.77 & $0.65-21.8$ \\
\hline
\end{tabular}

"Adjusted for center, maternal age, mother's socioeconomic status, urbanization, and country of origin. 
We then selected for multivariate analysis the exposures associated with an odds ratio for which the P-value was $20 \%$ or less: 15 for $\mathrm{CL}(\mathrm{P})$ and 32 for $\mathrm{CP}$ (table 4).

Some of the exposures were highly correlated, and we therefore made some arbitrary decisions. Of the chemical products or end use products associated only with hairdressers (hair dust, polyvinyl acetate, ammonia, aromatic amines, and bleaching agents), we chose only 1 (hair dust) to be representative of hairdressers. Some exposures were hierarchically organized; that is, for example, formaldehyde represented more than $95 \%$ of the aliphatic aldehydes. Ethanol and methanol were similarly hierarchically related to aliphatic alcohols. In these situations we considered the exposure that was representative of the chemical family (ie, aliphatic aldehydes, aliphatic alcohols). Spray gases and engine emissions (gasoline) were considered as possible end-use products for fluorocarbons and lead compounds, respectively. In our sample, all the women exposed to spray gases or engine emission were also coded as exposed to fluorocarbons or lead compounds. Only $50 \%$ of the fluorocarbons were used as spray gases, however, and $82 \%$ of the lead compounds resulted from engine emissions. We therefore selected the chemical products (fluorocarbons and lead compounds) instead of the end-use products. At the end of this process, we kept 11 exposures for CL(P) and 22 for CP.

For each type of cleft, the exposures were included in a backward stepwise logistic regression model with the adjustment variables presented earlier. Three exposures were retained for CL(P); 2 of these - aliphatic aldehydes and glycol ethers - were associated with an excess risk (table 5). The 3rd, which involved exposure to the duplicating process, showed an inverse relation with $\mathrm{CL}(\mathrm{P})$. At the end of the logistic regression, 5 exposures remained in the global CP model (table 6): lead compounds, trichlorethylene, aliphatic acids, biocides, and antineoplastic drugs. Forward or backward stepwise procedures gave the same results. Adjusting for tobacco use and alcohol consumption during the first trimester of pregnancy did not alter these results (table 5-6).

We also compared the results obtained by estimating risk for individual exposures separately (the univariate analysis) and by simultaneous (multivariate) evaluation. Four occupational exposures were associated with an odds ratio that was statistically different from $1(\mathrm{P}<0.05)$ for $\mathrm{CL}(\mathrm{P})$ in the estimation of individual risks (table 4): aliphatic aldehydes, glycol ethers, cleaning agents, and the duplicating process. After the competitive selection of 11 exposures with $P$-values of $\leq 0.20,3$ of these remained associated with the risk of $\mathrm{CL}(\mathrm{P})$. The end-use product group of cleaning agents was no longer included in the model, but much of its information was already included, with exposure to aliphatic aldehydes and glycol ethers ( $70 \%$ of exposure to glycol ethers occurred through the use of cleaning agents).

In the CP group, 14 exposures were individually associated with a statistically significant increased risk $(\mathrm{P}<0.05)$. After we eliminated structurally related exposures, 11 statistically significant associations remained. After competitive selection, only 5 exposures remained significantly associated with the risk of CP.

Table 7 summarizes the primary occupations of the mothers exposed to substances found to be significantly associated with an increase in oral clefts. Some exposures

Table 5. Last step of the global model, including 11 significant exposures ( $\leq 20 \%)$, for cleft lip with or without cleft palate.

\begin{tabular}{lcccccccc}
\hline Exposures & $\begin{array}{c}\text { Referents } \\
(\mathrm{N}=751)\end{array}$ & $\begin{array}{c}\text { Cases } \\
(\mathrm{N}=64)\end{array}$ & $\begin{array}{c}\text { Odds } \\
\text { ratio }\end{array}$ & $95 \% \mathrm{Cl}$ & P-value & $\begin{array}{c}\text { Odds } \\
\text { rati }\end{array}$ & $95 \% \mathrm{Cl}$ & $\mathrm{P}$-value \\
\hline Aliphatic aldehydes & 32 & 7 & 2.1 & $0.8-5.9$ & 0.16 & 4.4 & $1.3-14.4$ & 0.02 \\
Glycol ethers & 137 & 23 & 1.7 & $0.9-3.3$ & 0.13 & 1.5 & $0.6-3.5$ & 0.40 \\
Duplicating process & 201 & 10 & 0.5 & $0.2-1.1$ & 0.08 & 0.4 & $0.1-1.1$ & 0.06 \\
\hline
\end{tabular}

adjusted for center, maternal age, mother's socioeconomic status, urbanization, and country of origin.

${ }^{b}$ Adjusted for center, maternal age, mother's socioeconomic status, urbanization, country of origin, and tobacco and alcohol consumption.

Table 6. Last step of global model, including 22 significant exposures ( $P \leq 20 \%$ ), for cleft palate only.

\begin{tabular}{|c|c|c|c|c|c|c|c|c|}
\hline Exposures & $\begin{array}{l}\text { Referents } \\
(\mathrm{N}=751)\end{array}$ & $\begin{array}{c}\text { Cases } \\
(N=36)\end{array}$ & $\begin{array}{l}\text { Odds } \\
\text { ratio }\end{array}$ & $95 \% \mathrm{Cl}$ & P-value & $\begin{array}{l}\text { Odds } \\
\text { ratio }\end{array}$ & $95 \% \mathrm{Cl}$ & P-value \\
\hline Lead compounds & 45 & 5 & 4.0 & $1.3-12.2$ & 0.03 & 4.9 & $1.2-19.2$ & 0.04 \\
\hline Trichlorethylene & 5 & 2 & 6.7 & $0.9-49.7$ & 0.09 & 7.8 & $0.8-71.8$ & 0.10 \\
\hline Aliphatic acids & 12 & 4 & 5.9 & $1.5-22.8$ & 0.02 & 7.6 & $1.3-42.6$ & 0.04 \\
\hline Biocides & 135 & 13 & 2.5 & $1.0-5.95$ & 0.05 & 1.9 & $0.6-6.4$ & 0.29 \\
\hline Antineoplastic drugs & 7 & 2 & 5.1 & $0.8-34.0$ & 0.13 & 4.4 & $0.3-73.5$ & 0.34 \\
\hline
\end{tabular}

adjusted for center, maternal age, mother's socioeconomic status, urbanization, and country of origin.

${ }^{b}$ Adjusted for center, maternal age, mother's socioeconomic status, urbanization, country of origin, and tobacco and alcohol consumption. 
Table 7. Principal occupations (\%) of women exposed to substances found to be significantly associated with the risk of oral clefts.

\begin{tabular}{|c|c|c|c|c|c|c|c|}
\hline Occupation & $\begin{array}{l}\text { Lead } \\
\text { compounds } \\
(N=56)\end{array}$ & $\begin{array}{l}\text { Trichloro- } \\
\text { ethylene } \\
(\mathrm{N}=9)\end{array}$ & $\begin{array}{l}\text { Aliphatic } \\
\text { acids } \\
(\mathbb{N}=18)\end{array}$ & $\begin{array}{l}\text { Biocides } \\
(N=168)\end{array}$ & $\begin{array}{c}\text { Antineo- } \\
\text { plastic } \\
\text { drugs } \\
(\mathrm{N}=10)\end{array}$ & $\begin{array}{l}\text { Aliphatic } \\
\text { aldehydes } \\
(N=43)\end{array}$ & $\begin{array}{c}\text { Glycol } \\
\text { ethers } \\
(\mathrm{N}=171)\end{array}$ \\
\hline Professional, technical workers & 42.9 & 22.2 & 33.4 & 55.4 & 70.0 & 32.7 & 13.0 \\
\hline Medical doctors, dental, veterinarians, pharmacist & 1.8 & 0 & 16.7 & 13.1 & 10.0 & 14.0 & 0.6 \\
\hline Nurses, midwives, medical X-ray technicians & 8.9 & 0 & 0 & 33.3 & 60.0 & 14.0 & 2.3 \\
\hline Teachers & 7.1 & 0 & 5.6 & 2.4 & 0 & 0 & 1.8 \\
\hline Architects, engineers and related technicians & 3.6 & 11.1 & 0 & 0 & 0 & 0 & 1.2 \\
\hline Social workers & 16.1 & 0 & 0 & 1.2 & 0 & 0 & 1.2 \\
\hline Other professional and technical workers & 5.4 & 11,1 & 11.1 & 5.4 & 0 & 4.7 & 5.9 \\
\hline Administrative, managerial workers & 1.8 & 0 & 0 & 0 & 0 & 0 & 1.8 \\
\hline Clerical workers & 10.7 & 22.2 & 0 & 4.2 & 0 & 0 & 9.4 \\
\hline Sales workers & 26.8 & 0 & 0 & 4.2 & 0 & 2.3 & 20.5 \\
\hline Service workers & 5.4 & 22.2 & 66.8 & 34.5 & 30.0 & 48.8 & 48.5 \\
\hline Housekeeping workers & 0 & 0 & 0 & 19.6 & 0 & 7.0 & 24.6 \\
\hline Nurses' aides & 1.8 & 0 & 5.6 & 8.9 & 20.0 & 20.9 & 4.1 \\
\hline Hairdressers & 0 & 0 & 55.6 & 1.8 & 0 & 20.9 & 7.0 \\
\hline Cook, waiters & 1.8 & 0 & 0 & 1.8 & 0 & 0 & 6.4 \\
\hline Other service workers & 1.8 & 22.2 & 5.6 & 2.4 & 10.0 & 0 & 6.4 \\
\hline Agricultural workers & 0 & 0 & 0 & 1.2 & 0 & 0 & 0 \\
\hline Production workers & 12.5 & 33.3 & 0 & 0.6 & 0 & 16.3 & 7.1 \\
\hline Textile workers & 1.8 & 11.1 & 0 & 0 & 0 & 4.7 & 0 \\
\hline Leather workers & 0 & 11.1 & 0 & 0 & 0 & 9.3 & 1.2 \\
\hline Other production workers & 10.7 & 11.1 & 0 & 0.6 & 0 & 2.3 & 5.9 \\
\hline Total & 100 & 100 & 100 & 100 & 100 & 100 & 100 \\
\hline
\end{tabular}

were specific to particular occupations, for example, antineoplastic drugs and health care workers. Other exposures, such as to lead compounds, were more widespread.

A more-detailed analysis of the exposure variables of the level, frequency, and reliability of exposure could be performed only when enough subjects were exposed to each product. This analysis showed that, for glycol ethers among isolated CL(P) cases, the risk increased with the level, frequency, and reliability of exposure and therfore confirmed the results of a previous publication (23). For trichloroethylene exposure among the CP patients, it also showed that risk increased with the level and frequency of exposure (ie, for frequency: odds ratio low $6.6,95 \%$ CL 0.6 - 79; odds ratio medium $13.9,95 \%$ CI $1.1-186$ ). This analysis did not allow us to observe any increase in risk with the level, frequency, or reliability of any of the other exposures selected by the final model; this result, however, was sometimes due to a lack of variability among the exposure indicators. For example, all exposure to antineoplastic drugs was low-level, low-frequency, and certain.

\section{Discussion}

Determining the role of chemical exposures in the occurrence of congenital malformations in humans is an important challenge. Most of our knowledge about the effects of chemical exposures on reproductive outcomes comes from animal data. Because the reproductive processes of each species seem unique, extrapolation from animal data is always uncertain. It becomes all the more difficult if we presume, as appears to be the case, that humans are at least as sensitive as the most sensitive animal species tested (30). This study attempts to obtain some information about reproductive toxins in the workplace.

Our analysis suggests that occupational exposure to some chemicals can present a hazard to the developing embryo that leads to an orofacial cleft. These chemicals include lead compounds, biocides, antineoplastic drugs, trichloroethylene and aliphatic acids for $\mathrm{CP}$ and aliphatic aldehydes and glycol ethers for CL(P). An important advantage of this investigation was that the exposure assessment was made by industrial hygiene experts. It helped to reduce possible recall bias and to standardize the assessments.

Some of the limitations of this work are due to the population's occupational distribution. Conclusions are necessarily limited to chemicals present in the occupations represented. For instance, because of the paucity of agricultural workers, we could not study pesticide exposures. Service and production workers were the 2 occupational groups in our population that were specifically associated with an increased risk. These results may be conservative, however, because overadjustment may have resulted from the adjustment for the mother's socioeconomic status. The only occupations with an odds ratio significantly greater than 1 were housekeeping and hairdressing. Reproductive disorders, including spontaneous abortions $(31,32)$ and major malformations (32), have previously been observed among hairdressers, but 
not to a statistically significant degree. It has been suggested that these effects are related to several specific chemicals to which this occupational group is exposed (33). A few studies have associated housekeeping workers with an increased risk of oral clefts $(21,34)$. Janitors, who perform essentially the same tasks as housekeeping workers, with the same chemicals, have also been reported to have reproductive disorders (preterm deliveries and stillbirths) (35). These different reproductive disorders may not all have causes relevant to the etiology of oral clefts, but they do indicate that the work environment in these occupations is harmful to the reproductive process.

As table 7 shows, some of the 7 products selected at the end are independent indicators of tasks, such as cleaning and disinfection, that might on the whole increase the risk of $\mathrm{CL}(\mathrm{P})$ or $\mathrm{CP}$. These particular chemical groups were selected at the end of the multivariate analysis, a finding that may have resulted from chance. The plausibility of these specific associations must therefore be evaluated together with additional evidence. Other products (such as lead compounds, aliphatic aldehydes, glycol ethers) are ubiquitous and not associated uniquely with 1 type of occupation or task. In these cases, an association with the specific product selected is more credible. It must be added that for most of these 7 exposures, the reliability of the exposures was rated as at least probable or certain.

Applying the selection process to occupational exposures resulted in multiple comparisons, and we cannot exclude the possibility that some results are due to chance. Nevertheless, this process gave us the opportunity to take into account the correlation between exposures. Obtaining the same results with the backward and forward procedures indicates that the procedure was robust. In addition, most of the exposures selected are biologically plausible. Animal experiments have suggested that all the exposures selected by the logistic regression model may be reproductive toxins (36); some epidemiologic evidence suggests that they have a similar effect on humans.

Indeed, antineoplastic drugs are among the most potent teratogens known, as both animal studies and human observations have shown $(36,37)$. They have also been linked to congenital malformations in epidemiologic studies $(38,39)$. Lead compounds are generally teratogenic in animal studies. Lead compounds may induce stillbirth and spontaneous abortion in humans (36, 40, 41). One study found prenatal exposure to lead to be associated with minor anomalies (42). Maternal occupational exposure to solvents (which may include trichloroethylene and glycol ethers) has been related to oral clefts (20-22). Moreover, solvents have been indirectly incriminated by studies that have found an excess risk of orofacial clefts among leather workers $(43,44)$.
The limited number of exposed subjects prevents us from drawing any firm conclusions. These results nonetheless suggest that further evaluation of the effects of maternal occupational exposures on orofacial clefts may lead to useful findings.

\section{Acknowledgments}

This study was supported by the following: in France, the Ministry of Research and the Ministry of Health; in Italy, the Emilia Romagna Regional Administration and Toscana Regional Administration; in The Netherlands, the Directorate General of Labor of the Ministry of Social Affairs and Employment; in Great Britain, the Health and Safety Executive (1/LMD/126/360/88) and Greater Glasgow Health Board (Research Support Group); in Europe, EUROCAT (European Registration of Congenital Anomalies) and BIOMED Concerted Action BMH1 CT93 1585 "Occupational Exposures and Congenital Malformations". We thank the "Association Recherche et Partage" for its financial support.

\section{References}

1. Institute of Hygiene and Epidemiology. Rapport EUROCAT no 6. Surveillance of congenital anomalies in Europe 19801992. Brussels: Institute of Hygiene and Epidemiology, 1995.

2. Andrews J, Mc Garry JM. A community study of smoking in pregnancy. J Obstet Gynaecol Br Common 1972;79:105773.

3. Ericson A, Källen B, Westerholm P. Cigarette smoking as an etiologic factor in cleft lip and palate. Am J Obstet Gynecol 1979;135:348-51.

4. Källen K. Maternal smoking and orofacial clefts. Cleft Palate Craniofacial J 1997;34:11-6.

5. Khoury MJ, Gomez-Farias M, Mulinare J. Does maternal cigarette smoking during pregnancy cause cleft lip and palate in offspring? Am J Dis Child 1989;143:333-7.

6. Dravet C, Julian C, Legras A, Magaudda A, Guerrini R, Genton $\mathrm{P}$, et al. Epilepsy, antiepileptic drugs, and malformations in children of women with epilepsy: a French prospective cohort study. Neurology 1992;42 suppl 5:75-82.

7. Abrishamchian J, Khoury MJ and Calle EE. The contribution of maternal epilepsy and its treatment to the etiology of oral clefts: a population-based case-control study. Genet Epidemiol 1994;11:343-51.

8. Werler MM, Lammer EJ, Rosenberg L and Mitchell A. Maternal alcohol use in relation to selected birth defects. Am J Epidemiol 1991;134:691-8.

9. Munger RG, Romitti PA, Daack-Hirsh S, Burns TL, Murray JC, Hanson J. Maternal alcohol use and risk of orofacial cleft birth defects. Teratology 1996;54:27-33.

10. Toralova M, Haris J. Reduced recurrence of orofacial clefts after periconceptional supplementation with high-dose folic acid and multivitamins. Teratology 1995;51:71-8. 
11. Shaw G, Lammer E, Wasserman C, O'Malley C, Toralova M. Risks of orofacial clefts in children born to women using multivitamins containing folic acid periconceptionally. Lancet 1998;346:393-6.

12. Hayes C, Werler M, Willet W, Mitchell C. Case-control study of periconceptional folic acid supplementation and oral clefts. Am J Epidemiol 1996;143:1229-34.

13. Erickson JD, Cochran WM, Anderson CE. Parental occupation and birth defects. Contrib Epidemiol Biostat 1979; $1: 107-17$

14. Hemminki, Mutanen P, Saloniemi I and Luoma K. Congenital malformations and maternal occupation in Finland: multivariate analysis. J Epidemiol Community Health 1981;35:5-10.

15. Mc Donald AD, Mc Donald JC, Armstrong B, Cherry NM, Coté R, Lavoie J. Congenital defects and work in pregnancy. Br J Ind Med 1988;45:581-8.

16. Taskinen HK. Effect of parental occupational exposures on spontaneous abortion and congenital malformation (review). Scand J Work Environ Health 1990;16:297-314.

17. Savitz DA, Olshan AF and Gallagher K. Maternal occupation and pregnancy outcome. Epidemiol 1996;7:269-74.

18. Thomas DC, Pettiti DB, Goldhaber M, Swan SH, Rappaport EB, Hertz-Picciotto I. Reproductive outcomes in relation to Malathion spraying in the San Francisco Bay Area, 19811982. Epidemiology 1992;3:32-9.

19. Nurminen T, Rantala K, Kurppa K, Holmberg PC. Agricultural work during pregnancy and selected structural malformations in Finland. Epidemiology 1994;6:23-30.

20. Holmberg PC, Hernberg S, Kurppa K, Rantala R, Riala R. Oral clefts and organic solvent exposure during pregnancy. Int Arch Occup Environ Health 1982;50:371—6.

21. Cordier S, Ha MC, Ayme S, Goujard J. Maternal occupational exposure and congenital malformations. Scand $\mathbf{J}$ Work Environ Health 1992;18:11-7.

22. Laumon B, Martin JL, Bertucat I, Vernet M, Robert E. Exposure to organic solvents during pregnancy and oral clefts: a case-control study. Reprod Toxicol 1996;10:15-29.

23. Cordier S, Bergeret A, Goujard J, Ha MC, Aymé S, Bianchi F, et al. Congenital malformations and maternal occupational exposure to glycol ethers. Epidemiology 1997;8:355—63.

24. British Paediatric Association. Classification of Diseases. 2nd ed. London: British Paediatric Association, 1987.

25. United Nations. International Standard Industrial Classification of all Economic Activities. New York (NY): United Nations, 1971.

26. International Labor Office. International Standard Classification of Occupations. Geneva: International Labor Office, 1968.

27. Saxen I. Cleft lip and palate in Finland: parental histories, course of pregnancy and selected environmental factors. Int J Epidemiol 1974;3:263-70.

28. Shaw GM, Croen LA, Curry CJ. Isolated oral cleft malforma- tions: associations with maternal and infant characteristics in a California population. Teratology 1991;43:225-8.

29. Womersley J, Stone DH. Epidemiology of facial clefts. Arch Dis Child 1987;62:717-20.

30. US Environmental Protection Agency. Guidelines for reproductive toxicity risk assessment part II. Fed Regist 1996; 61(212).

31. John EM, Savitz DA, Shy CM. Spontaneous abortion among cosmetologists. Epidemiology 1994;5:147-54.

32. Kersemaekers WM, Roeleved N, Zielhuis GA. Reproductive disorders among hairdressers. Epidemiology 1997;8:396401.

33. Kersemaekers WM, Roeleved N, Zielhuis GA. Reproductive disorders due to chemical exposure among hairdressers (review). Scand J Work Environ Health 1995;21:325-34.

34. Holmberg P, Hernberg S. Congenital defects and occupational factors: a comparison of different methodological approaches. Scand J Work Environ Health 1979;5:328-32.

35. Savitz DA, Olshan A and Gallakher K. Maternal occupation and pregnancy outcome. Epidemiology 1996;7:269-74.

36. Shardein JL. Chemically induced birth defects. 2nd ed. New York (NY): Marcel Dekker, 1993.

37. Kline J. Maternal occupation: effect on spontaneous abortions and malformations. Occup Med 1986;1:381—403.

38. Hemminki K, Kyyrönen P, Lindbohm ML. Spontaneous abortions and malformations in the offspring of nurses exposed to anaethesic gases, cytostatic drugs and other potential hazards in hospitals, based on registered information of outcome. J Epidemiol Community Health 1985;313:141-7.

39. Ahlborg G, Hemminki K. Reproductive effects of chemical exposures in health professions. J Occup Environ Med 1995;37:957-61.

40. Savitz DA, Whelan EA, Kleckner RC. Effect of parents' occupational exposures on risk of stillbirth, preterm delivery, and small-for-gestational-age infants. Am J Epidemiol 1989:129:1201-18.

41. Antilla A, Sallmen M. Effects of parental occupational exposure to lead and other metals on spontaneous abortion. J Occup Environ Med 1995;37:915-21.

42. Needlman HL, Rabinowitz M, Leviton Md, Linn S, Shoenbaum $S$. The relationship between prenatal exposure to lead and congenital anomalies. JAMA 1984:251:2956-9.

43. Bianchi F, Cianciulli D, Pierini A, Seniori Constantini A. Congenital malformations and maternal occupation: a registry based case-control study. Occup Environ Med 1997;54:2238.

44. Garcia A, Fletcher T. Maternal occupation in the leather industry and selected congenital malformations. Occup Environ Med 1998;55:284-6.

Received for publication: 28 January 1999 